\title{
Resenha
}

\section{PESQUISAR A PESQUISA: TRAJETÓRIA E PROBLEMATIZAÇÕES DE UMA PRÁTICA INVENTIVA} INVESTIGAR LA INVESTIGACIÓN: TRAYECTORIA Y PROBLEMATIZACIONES
DE UNA PRACTICA INVENTIVA
SEARCH THE SEARCH: PATH AND PROBLEMATIZATIONS OF A
INVENTIVE PRACTICE

João Henrique de Sousa Santos e Luciana Kind do Nascimento Pontifícia Universidade Católica de Minas Gerais, Belo Horizonte/MG, Brasil

Rosineide de Lourdes Meira Cordeiro

Universidade Federal de Pernambuco, Recife/PE, Brasil

\section{Resenha de}

Zanella, A. V. (2013). Perguntar, registrar, escrever: inquietações metodológicas. Porto Alegre: Sulina; Editora da UFRGS.

O entendimento da pesquisa como produção de conhecimento e uma experiência de si, serve como fundamento e orienta o livro Perguntar, registrar, escrever: inquietações metodológicas, de Andréa Zanella. Por meio de uma escrita que por vezes assume um tom poético, a autora problematiza a pesquisa e o pesquisar como um movimento de criação, uma prática inventiva, inserida em um processo dinâmico. Ao cartografar os caminhos da pesquisa, distancia-se de um fazer ciência ligado ao discurso do método, e se aproxima de uma prática que envolve encontros, afetamentos e relações estéticas. Suas inquietações compõem uma trajetória que reúne ciência, arte e vida. Da questão que conduz à investigação ao retorno e divulgação da pesquisa, a autora expõe seu trabalho, em meio às inquietações metodológicas, com elementos que convidam leitoras e leitores a prática do pesquisar a própria pesquisa. Neste livro, a autora faz emergir a pesquisadora e escritora; atributos visíveis e correlatos a uma produção que é, especialmente, uma escrita de si.

É especialmente no campo da pesquisa que a obra em questão se torna tão importante. Primeiramente, pela problematização de uma prática cotidiana no universo acadêmico, com relevância social e objetivando a produção de novos conhecimentos. Em segundo lugar, pela promoção de estratégias metodológicas singulares, promovendo uma reinvenção da escrita na pesquisa, assim como estratégias de encontro com os dados e análises que podem compor a investigação.
Por último, mas não menos importante, pelo diálogo multidisciplinar (psicologia, antropologia, sociologia, filosofia e linguística) em direção a uma crítica às racionalidades totalizantes, ampliação do debate e abertura de novos modos de se fazer pesquisa.

$\mathrm{O}$ pesquisar exige um desprendimento das formas e objetos, é estar aberto às imprevisibilidades que movimentam as previsibilidades metodológicas. O exercício de pesquisar envolve atravessamentos que permeiam a relação do pesquisador com os múltiplos agenciamentos e que possibilitam, pela prática, a emergência do novo, acontecimentos que se fazem em meio a composição do trabalho. Essa produção, emergência como acontecimento, é distinta da noção de criação. Trata-se da emergência de uma singularidade, a necessidade de esquadrinhar as evidências que apoiam o saber e as práticas, em uma investigação sem produtor e sem produto, no qual ambos se fazem no mesmo processo. (FOUCAULT, 2003). Tomar o acontecimento no âmbito investigativo consiste na possibilidade da irrupção de singularidades no processo de construção.

As problematizações da prática de pesquisa estão distribuídas ao longo da introdução e sete capítulos. Compõe o livro, ainda, o prefácio assinado por Mássimo Canevacci. Vale ressaltar que, à convite da autora, o leitor pode optar por fazer uma leitura descontínua, construindo um percurso singular. No primeiro capítulo, intitulado "Algumas palavras da/ sobre a densa e espessa selva que me envolve e constitui”, a autora relata sua trajetória, caminhos que produziram modificações em seu olhar e promoveram investigações no encontro entre pesquisador e realidade pesquisada.

Em "Pesquisar e/é criar, ciência e/é arte, arte e/é vida", capítulo II, Zanella defende a arte, ciência 
e vida como dimensões da existência humana. Para embasar essa discussão, utiliza o imaginar e criar como condição do humano, fundamento do devir, instâncias de movimentos e recriação das singularidades, a emergência do sujeito em sua multiplicidade, potência. Esse que emerge é um sujeito ativo, expect-ator, que se reinventa mediante o encontro com o outro, produzindo afetamentos e instabilizando o aparentemente estável. Pesquisador e artista se encontram na medida em que a esses cabe a "(re)invenção constante da própria existência, somase a criação em seu campo de conhecimento, a criação na esfera da ciência que (...) entretece arte, ciência e vida". (p. 45).

"Sobre começos e recomeços...", capítulo III, propõe uma discussão metodológica, pautada na temática que orientará o pesquisador no percurso investigativo, a saber, a questão de pesquisa. Perguntar é preciso, e a direção da investigação dependerá de uma formulação clara, que expõe ao autor e leitor os rumos que a pesquisa irá tomar. Nesse território, a leitura possibilita saber o que já foi apreendido e o que precisa ser descoberto, as linhas que compõem uma tessitura já formada e outras que precisam ser retiradas para desvendar novos caminhos.

A imagem aparece no capítulo IV, "Imagem e a/na aventura do pesquisar", como material que contribui para a produção de sentido, a captura de um determinado acontecimento, demarcado no tempo e no espaço, e cria possibilidades variadas de investigação dos dizeres em meio à sequência narrativa. Zanella, nesse capítulo, convida a uma aventura pelos modos de olhar e registrar o que se vê, uma reinvenção dos modos de ser-estar em campo, uma refração no cruzamento entre arte e psicologia, aludindo que um olhar mais atento pode descobrir na imagem o não dito das linhas textuais, o entrelinha revelado na cena.

Em "Sobre o processo de criação da/na escrita da pesquisa", capítulo $\mathrm{V}$, a palavra ganha vida, potência, idas e vindas no embate entre o dito e o contratido, palavra que anuncia seu autor e a realidade em questão. A escrita no processo de pesquisar surge como possibilidade de desvendar os atores que compõe a tênue rede de intensidade variadas. Intencionalidades múltiplas que reverberam nos encontros com a palavra, com o outro, com o singular. O exercício da escrita modifica a relação que o sujeito estabelece com o presente, levando-o a uma (re)invenção da prática e, consequentemente, à experiência de novos modos de ser, pensar, olhar, perguntar, registrar, escrever. A escrita, enquanto ação, assume lugar de singularização, produzindo uma experiência de afecção, que remete a uma função estética de criação de si mesmo. Em diálogo com Foucault (2009), a escrita compõe o processo de reinvenção de si próprio, arte de viver, exercício de si em um modo de subjetivação sobre si mesmo. Longe da lógica da reprodução, uma escrita promove a disparidade dos conceitos, que devem ser desdobrados em múltiplos significados.

A pesquisa é, nesta obra, defendida como prática social e, como tal, é no encontro com os múltiplos que o pesquisador (re)cria-se. Os encontros e os afetamentos que eles produzem são discutidos no capítulo seguinte: "Escrever e/é (re)criar(se)". As tensões e produções, efeito do encontro com o(s) outro(s) da pesquisa, configura um campo ético, estético e político do ato de pesquisar, argumenta Zanella.

Finalmente, o último capítulo, "A comunicação da pesquisa e alguns de seus destinatários e desafios", tão importante pela questão ética que o circunscreve, discute o produto da pesquisa e sua função no cenário social e científico. Para além da produção de conhecimento, é fundamental compartilhar os dados da pesquisa com seus participantes. A pesquisa, enquanto prática social, deve ser "comprometida com uma perspectiva de sociedade que considera o desenvolvimento científico e tecnológico como patrimônio cultural e, mais especificamente, como direito de todos". (p. 165).

Zanella convida a pensar que ao pesquisador cabe um olhar difuso, retroativo, que movimenta-se em direção ao outro e volta-se para si, um olhar que se interage com o que vê. A figura do pesquisador, implicada no ato revolucionário que permeia esse encontro, produz uma prática que explicita o movimento de (re)constituição do sujeito expectactor. A experiência ganha vida e se apresenta em sua dimensão ontológica, estética, ética e política. Rompe-se com discursos estruturantes, coisificantes, com imagens estáticas e modula-se um espaço de potência criativa, inventiva e realizadora.

No campo da Psicologia Social esta obra promove a compreensão da experiência de pesquisa, para além do quadro de experimentação científica, questionando o universal/natural/estático e problematizando os acontecimentos, levando o pesquisador a se reconhecer como sujeito de sua prática. A dimensão ética e política que envolve a (trans)formação do eu em sujeito, mediante o encontro com o outro, é fruto de uma prática crítica e aberta às múltiplas vozes que compõe o cenário social. Pesquisar é assumir os papéis variados que o campo promove, é lançarse à cena e atuar de forma com que o pesquisador/ personagem ganhe vida e adentre ao cenário para construir a narrativa e promover reinvenções nos 
modos de se fazer pesquisa. Estudantes, profissionais e pesquisadores de diferentes áreas, encontrarão no livro de Zanella inspiração, reflexão e conhecimentos que poderão alimentar variados modos de pesquisa.

\section{Referências}

Foucault, M. (2003). Estratégia poder-saber. Rio de Janeiro: Forense Universitária.

Foucault, M. (2009). O que é um autor? Lisboa: Nova Veja Limitada.

João Henrique de Sousa Santos é graduado em Psicologia pela Pontifícia Universidade Católica de Minas Gerais

(2012). Mestrando em Psicologia pela PUC Minas. Bolsista

CAPES. Endereço: Rua Elesbão de Araújo Medeiros, 84. São Marcos. Belo Horizonte/MG, Brasil. CEP 31.930-310.

E-mail: jhsousasantos@gmail.com

Luciana Kind do Nascimento é Pós-doutor em Psicologia Social (UFMG). Doutora em Saúde Coletiva pelo Instituto de Medicina Social da Universidade do Estado do Rio de Janeiro (2007), tendo realizado estágio doutoral no Instituto
Max Planck para a História da Ciência em Berlim (2005). Mestre em Psicologia Social pela Universidade Federal de Minas Gerais (2003). Graduação em Psicologia pela Universidade Federal de Minas Gerais (1996). É professora no Programa de Pós-Graduação em Psicologia da Pontifícia Universidade Católica de Minas Gerais. E-mail: lukind@gmail.com

Rosineide de Lourdes Meira Cordeiro possui graduação em Serviço Social pela Fundação Universitária de Apoio ao Ensino Pesquisa e Extensão (1986), mestrado em Serviço Social pela Universidade Federal de Pernambuco (1995) e doutorado em Psicologia (Psicologia Social) pela Pontifícia Universidade Católica de São Paulo (2004). É professora do Programa de Pós-graduação em Psicologia da UFPE. E-mail: rocordeirope@gmail.com

\section{Como citar:}

Santos, J. H. S., Nascimento, L. K., \& Cordeiro, R. L. M. (2014). Pesquisar a pesquisa: trajetória e problematizações de uma prática inventiva. Psicologia \& Sociedade, 26(2), 528-530. 